\title{
SÍNTESIS HISTÓRICA DEL POBLAMIENTO DE LA REGIÓN FRONTERIZA MÉXICO-ESTADOS UNIDOS
}

\author{
Por \\ Manuel Ceballos Ramírez* \\ Lawrence Douglas Taylor H.*
}

\begin{abstract}
RESUMEN
En este artículo se describe la trayectoria del poblamiento en los estados fronterizos del norte de México, así como, en forma resumida, la del pueblo mexico-americano de Texas y los estados del suroeste de Estados Unidos. Se destaca, sobre todo, la época porfiriana como etapa clave en este proceso. También se hace hincapié en el extraordinario incremento de la población fronteriza mexicana, especialmente la de los centros urbanos situados a lolargo de la línea divisoria, durante la década de 1920, la segunda guerra mundial y los años de posguerra. Se dedica atención, en particular, a los cambios en los patrones de inmigración y colonización para el período estudiado, así como el fenómeno de la repatriación de mexicanos desde el fin de la guerra México-Estados Unidos hasta la crisis económica de la década de 1980.
\end{abstract}

\begin{abstract}
This article describes the trajectory of the human settlements in the border states of northern Mexico, as well as the Mexican-American population of Texas and the Southwest. It is emphasized, above all, the era of the Porfirio Díaz regimen key epoch in this process. It also points out the extraordinary increase of the border population of northern Mexico, specialy of those urban settlements located along the border line during the decade of 1920's, the Second World War and the postwar years. It draws attention, in particular, to the change of immigrating and colonization standards for the studied period, as well as the phenomenon of Mexicans repatriation since the end of the United States-Mexico war up until the economic crisis of the 1980's.
\end{abstract}

\section{INTRODUCCIÓN}

El establecimiento de la línea divisoria entre México y Estados Unidos, de acuerdo con las estipulaciones del Tratado de Guadalupe Hidalgo de 1848, marcó el verdadero inicio del poblamiento de la región fronteriza

* Investigadores del Colegio de la Frontera Norte. 
entre ambos países, que, para los propósitos de este trabajo, se define como la zona que comprende los estados actuales de Baja California, Sonora, Chihuahua, Coahuila, Nuevo León y Tamaulipas; y, del lado estadounidense, las entidades de California, Arizona, Nuevo México y Texas. Al considerar que la población mexicana constituye el componente más importante y representativo del mosaico poblacional de esta zona inmensa, se ha decidido limitar el estudio a una consideración de este grupo, a la exclusión de otros pobladores, como los diferentes pueblos indígenas y miembros de otros grupos étnicos o raciales (inglés, alemán, chino, ruso, negro, filipino, etc.), que deben ser objeto de otras investigaciones.

\section{EL PORFIRIATO}

Desde la delimitación de la frontera en 1848 hasta la década de 1880 , el poblamiento de los estados y territorios fronterizos de México fue un proceso relativamente lento (véase figura 1) debido a las luchas civiles (principalmente la reforma y la intervención francesa), a la falta de comunicaciones y transporte y a la escasez de recursos naturales en la región (particularmente el agua para la agricultura y la ganadería), así como al peligro de asaltos por bandoleros e indios merodeadores. En términos generales, el tipo de población más común en el norte de México era la comunidad minera.

A lo largo de la línea divisoria, los asentamientos humanos frecuentemente estaban agrupados en las cercanías de las colonias militares y aduanas. Las colonias militares, creadas en 1849, habían reemplazado a las antiguas compañías permanentes establecidas en 1834, que, a su vez, habían sustituido a los presidios del período colonial. Con el tiempo, varias de ellas se convertirían en las poblaciones fronterizas de hoy en día. ${ }^{1}$

Fue durante la administración del presidente Porfirio Díaz (1876 a 1911), cuando los estados fronterizos mexicanos recibieron sus primeros estímulos poblacionales importantes. El desarrollo de los ferrocarriles, y, a su vez, de la minería, especialmente a partir de la década de 1880, impulsó la creación de amplios mercados regionales en los centros urbanos norteños. La construcción de líneas ferroviarias que conectaban el centro del país con la frontera estadounidense estimuló grandemente el movimiento de la población desde el centro del país hacia el norte. Entre las ciudades mexicanas que experimentaron un auge económico y poblacional durante

1 Por ejemplo, la colonia militar de Guerrero, Coahuila, establecida en 1850, formó el núcleo de la actual ciudad de Piedras Negras (para un estudio más amplio consultar a: David Piñera, 1987 V. 2:217-220, 265, 305-307; Ham, 1987:6). 


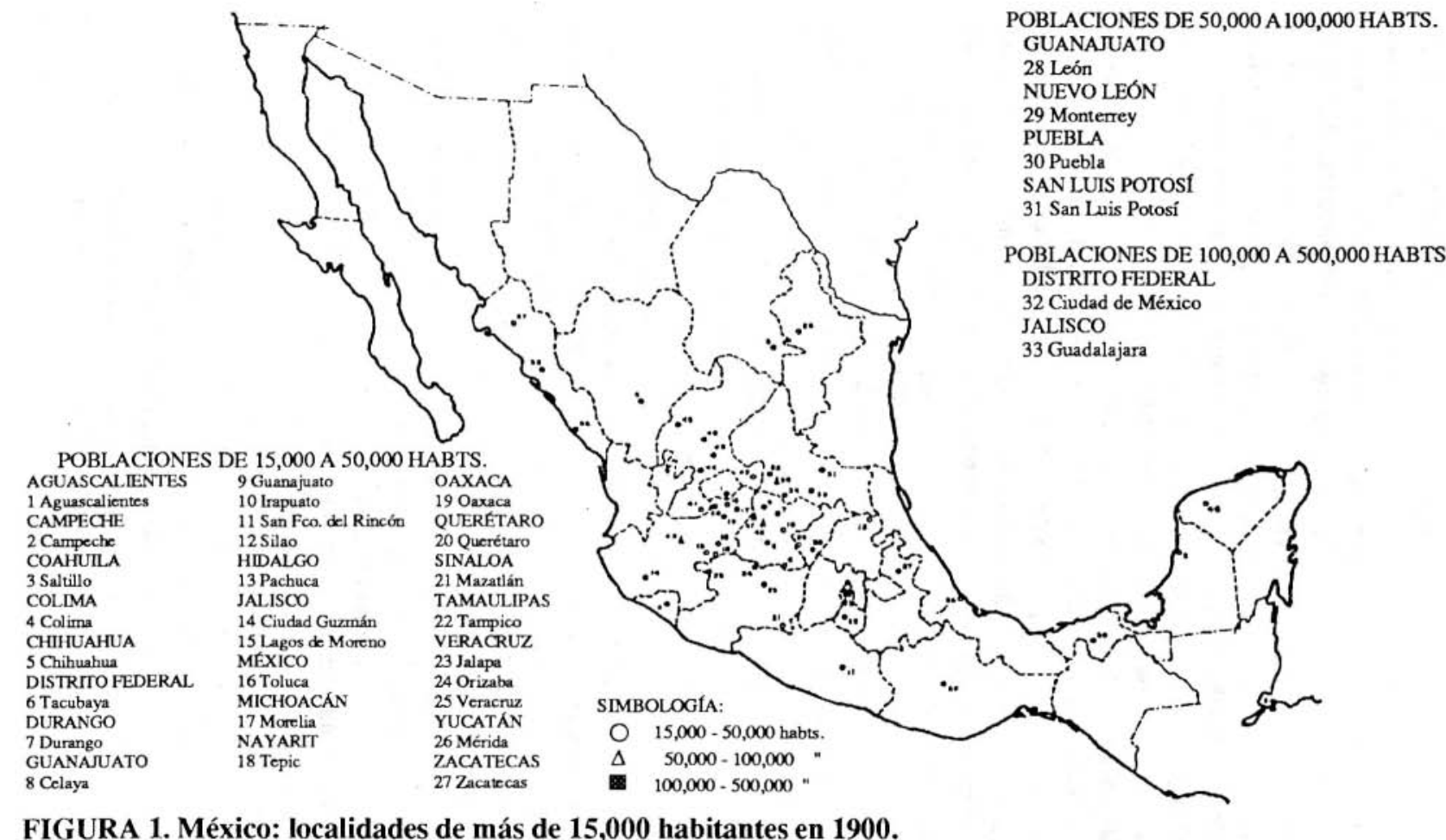

FIGURA 1. México: localidades de más de 15,000 habitantes en 1900.

FUENTE: Luis Unikel, et al. El desarrollo urbano de México: diagnóstico e implicaciones futuras (1978: 23). 
este período se encontraban Monterrey, en donde se establecieron plantas beneficiadoras de productos mineros; Torreón y Chihuahua, debido al desarrollo del cultivo del algodón y de la ganadería respectivamente; Saltillo, ciudad favorecida por el desarrollo comercial, la ubicación del poder público estatal y la relativamente buena comunicación. También hubo aumentos de población en algunas localidades más pequeñas, como Hermosillo y Cananea, en Sonora, donde a finales del siglo XIX fueron establecidas fundiciones en las que se trabajaban el cobre y el plomo.

El desarrollo económico de la época también influyó en el poblamiento de la franja a lo largo de la línea divisoria internacional. Nogales, Agua Prieta y Naco, en Sonora, nacieron al llegar las vías del ferrocarril a estos puntos. Ensenada, Tijuana y Mexicali, del Distrito Norte de Baja California, surgieron como resultado de diferentes actividades económicas de la época. Ciudad Juárez, Chihuahua, se convirtió en un importante destino ferroviario, mientras que Ciudad Porfirio Diaz (hoy Piedras Negras) y Las Vacas (la actual Ciudad Acuña), Coahuila, y Nucvo Laredo, Tamaulipas, crecieron en parte debido al flujo de mercancías a través de sus aduanas (Unikel, et al., 1978:36-37; Piñera y Padilla, 1987, V. 2:429-430).

Motivado por las ideas corrientes de la época, que sostenían que una nación podía realizar sus metas de desarrollo económico y social a través de la inmigración, el gobierno porfiriano también intentó establecer asentamientos de colonos en las zonas menos habitadas del país, sobre todo en el norte. De 1878 a 1910 , se concertaron 156 contratos de colonización con la Secretaría de Fomento, la mayoria de los cuales trataban proyectos de colonización de los estados y territorios en el norte del país, especialmente en Baja California, Sonora y Chihuahua. El gobierno prefirió que se asentaran en estas regiones colonos de procedencia europea, sobre todo los que compartían una cultura "latina", como los españoles (especialmente los agricultores de las islas Canarias), los italianos, los belgas y los franceses. Asimismo favoreció, aunque en menor grado, la inmigración de alemanes, irlandeses, ingleses, rusos, egipcios, bóers, polinesios, chinos y japoneses. También intentó atraer como colonos potenciales a los estadounidenses, canadienses, caribeños, sudamericanos, así como mexicanos residentes en Estados Unidos y Guatemala.

De todos estos proyectos, sólo llegaron a formarse 60 colonias (16 oficiales y 44 particulares), de las cuales, más de la mitad fueron fundadas en los estados de la frontera norte y del noroeste. Veintitrés fueron constituidas con mexicanos de otras regiones de México y del extranjero; $y$, de los 37 asentamientos restantes, 20 fueron formados con colonos estadounidenses. En Chihuahua, estado en que se fundó el mayor número de colonias, únicamente dos de ellas fueron establecidas bajo los auspicios 
del gobierno federal y con colonos mexicanos; las demás fueron creadas por particulares (dos de ellas mexicanas, una belga, una boera y diez estadounidenses). ${ }^{2}$

\section{LOS COMIENZOS DEL GRAN CRECIMIENTO POBLACIONAL: 1900-1940}

A pesar de estos movimientos de población y esfuerzos para colonizar el norte, la región quedaba relativamente poco poblada al principiar el siglo XX (véase figura 2). Hacia el noroeste, en los estados de Sonora y Sinaloa, y en los territorios de Nayarit y Baja California, había sólo 716,000 habitantes. La península de Baja California contaba con una pequeña proporción de esta población, estimada en 50,000 habitantes aproximadamente. El noroeste, junto con el estado de Tamaulipas en el noreste, también se tipificaba a principios del siglo entre las zonas menos urbanizadas del país. Para ese entonces, contaba con 120,000 habitantes en sus áreas urbanas, mientras que el 90 por ciento de la población vivía en localidades rurales. La región del norte, que comprende los estados de Chihuahua, Coahuila, Durango y Nuevo León, sólo contaba con una ciudad importante, la de Monterrey, que por entonces tenía menos de 100,000 habitantes (Davis, 1972:508-511; Unikel, et al., 1978:73).

De 1900 a 1940, el México septentrional, especialmente la zona fronteriza, empezó a urbanizarse rápidamente. Esta aceleración en el proceso de la urbanización se debió, en el caso del noroeste, al comienzo de una industria agrícola moderna con cultivos para la exportación; en el noreste, al crecimiento de la minería y fundición de metales, con centro principal en Monterrey; $y$, en toda la extensión de la frontera, al surgimiento de actividades de servicios. También fue resultado del aumento en la infraestructura de las comunicaciones y transportes del país que, entre otras cosas, facilitó durante y después de la lucha armada de 1910 a 1921, la migración hacia las ciudades existentes desde tiempos coloniales o de

\footnotetext{
2 Las dos colonias de mexicanos oficiales se ubicaban en Ascención, mientras que las particulares se situaban en los pueblos de Arteaga y Janos (la segunda estaba poblada por mexicanos repatriados de Estados Unidos). La colonia belga se ubicaba en San Francisco de Conchos, y la de los bóers en Santa Rosalía. Las colonias estadounidenses estaban situadas en Palomas, cerca de la línea internacional, y en Chuichupa, Porfirio Díaz, Manuel Dublán, Femández Leal, García, Guadalupe, Hidalgo, Juárez, y Carlos Pacheco, cerca de Casas Grandes en el distrito de Galeana. Con excepción del de Palomas, todos estos asentamientos estaban poblados por colonos mormones. Véase Moisés González Navarro (1960:5, 54, $63-70,76-77,117$ y 122) y Enrique Cortés (1979:2-4).
} 


POBLACIONES DE 15,000
A 50,000 HABTS.
AGUASCALIENTES
1 Aguascalientes
CAMPECHE
2 Campeche
COAHUILA
3 Saltillo
COLIMA
4 Colima
DURANGO
5 Durango
GUANAJUATO
6 Acambaro
7 Dolores
8 Salamanca
9 San Felipe
10 San Miguel Allende
GUERERO
11 Chilapa
HIDALGO
12 Nuejutla
JALISCO
13 Atotonilco
14 Autlán
15 Encarnacionn
16 La Barca
17 Lagos de Moreno
18 Ocotlán
19 San Juan de los Lagos
20 Teocaltiche
MICHOACÁN
21 Huetamo

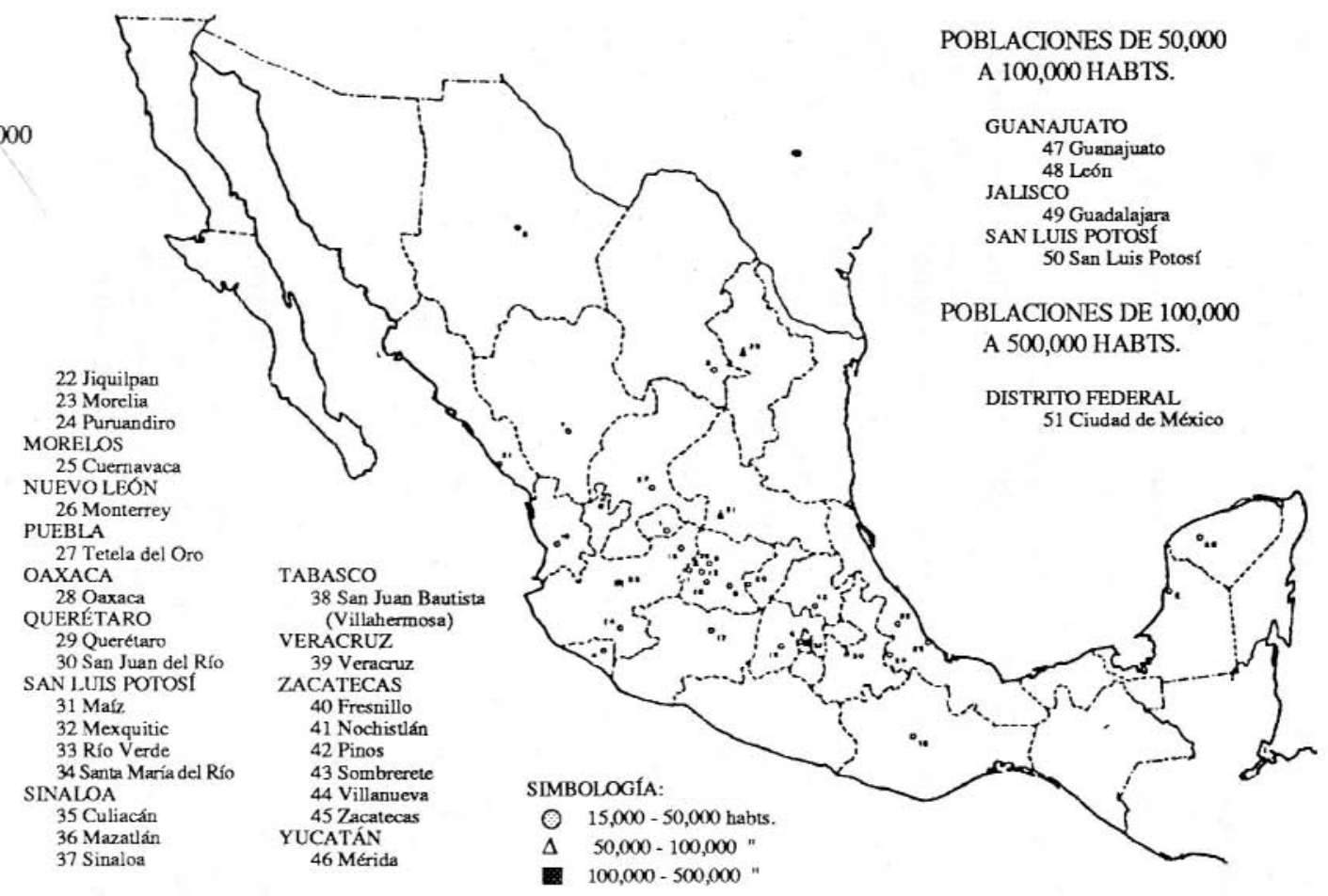

FIGURA 2. México: Localidades de más de 15,000 habitantes en 1878.

FUENTE: Luis Unikel, et al. El desarrollo urbano de México: diagnóstico e implicaciones futuras (1978: 38). 
reciente creación, como las de Tijuana y Mexicali en Baja California. Cabe señalar que, referente a las poblaciones situadas a lo largo de la línea divisoria, más del 90 por ciento de la gente vivía en Ciudad Juárez, Piedras Negras, Matamoros y Nuevo Laredo, mientras que entre Tijuana y Ciudad Juárez únicamente había unos tres mil habitantes (véase figura 3) (Unikel, 1978:77; Ham, 1987:7).

Durante la década revolucionaria de 1910 a 1920, hubo una reducción sustancial en el crecimiento económico y demográfico del país en general. La violencia de la lucha, la prevalencia de desnutrición y enfermedades, así como una caída en el índice de nacimientos, tuvo como consecuencia una disminución de la población en muchos pueblos y ciudades de los estados fronterizos. Cabe notar, empero, que las localidades urbanas a lo largo de la línea divisoria experimentaron un fuerte aumento demográfico durante esta época. Las del lado mexicano de la frontera (es decir, aquéllas con más de 15,000 habitantes) crecieron de 52,000 a 96,000 habitantes, o sea, casi el doble. Quizás el factor más importante en este incremento se debe a los miles de refugiados políticos y de la gente en general que emigraron rumbo a Estados Unidos en busca de la seguridad, pero no lograron cruzar y permanecieron en el lado mexicano (González, 1974:72-73; Unikel, et al., 1978:22-23 y 36-38; Ham, 1987:7 y 9).

Al iniciarse la etapa constructora de la revolución, de 1920 a 1930 , varias ciudades fronterizas volvieron a prosperar, en gran parte debido a la normalización del comercio exterior terrestre con Estados Unidos, así como a la famosa Acta Volstead o "Ley Seca" de ese país, que estimuló enormemente los negocios del lado mexicano que dependían de la venta de licores. La población de Tijuana, por ejemplo, creció de 1,028 habitantes en 1921 a 8,384 en 1930, mientras que la de Ciudad Juárez creció de 19,457 a 39,669. El aumento también se debió al importante desarrollo algodonero de la región lagunera y los valles contiguos a varias ciudades fronterizas como Matamoros (Unikel, et al., 1978:37; Martínez, 1982:90-94 y 213).

Durante la gran depresión de 1930 a 1939 , el crecimiento de la población urbana fronteriza se desaceleró notablemente. El incremento poblacional de Ciudad Juárez y de las demás ciudades de la frontera virtualmente se frenó a raíz de la disminución en la exportación e importación de productos primarios y mercancías de todo tipo por la frontera norte. Monterrey, por el contrario, mantuvo un importante ritmo de crecimiento. Sin embargo, para 1940, los estados fronterizos de México en general todavía estaban poco poblados, con enormes regiones desérticas y con ciudades muy dispersas (véase figura 4). 


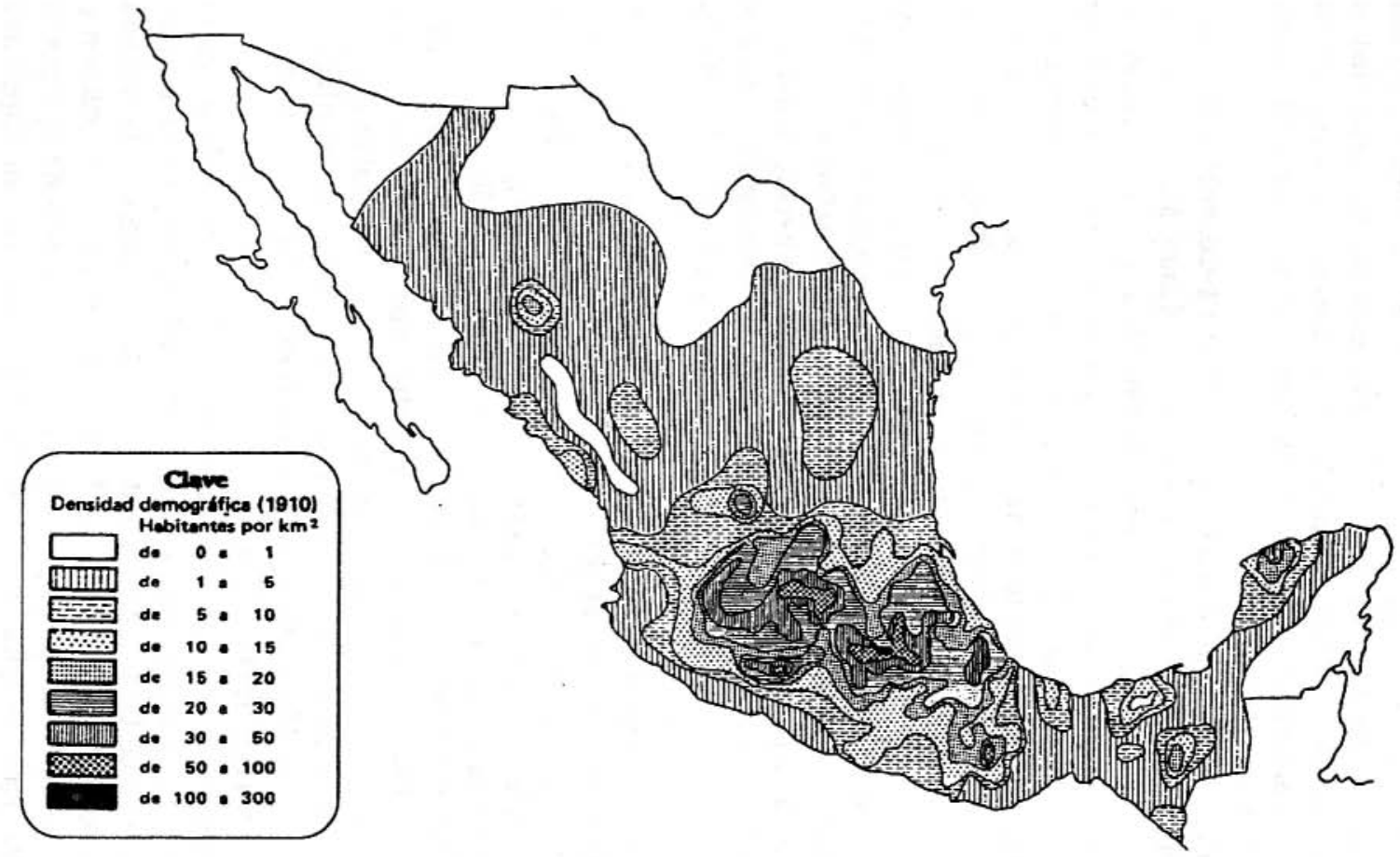

FIGURA 3.

FUENTE: Enrique Florescano. Atlas histórico de México (1983: 129). 


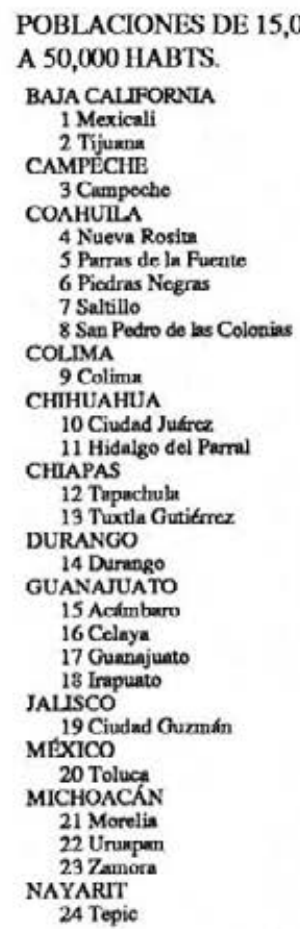

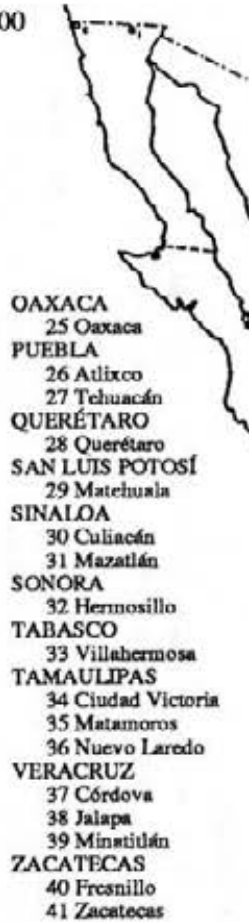

POBLACIONES DE 50,000 A 100,000 HABTS.

FIGURA 4. México: Localidades de más de 15,000 habitantes en 1940.

FUENTE: Luis Unikel, et al. El desarrollo urbano de México: diagnostico e implicaciones futuras (1978:39). 


\section{DE LA SEGUNDA GUERRA MUNDIAL A LA DÉCADA DE 1980}

Como resultado indirecto de la segunda guerra mundial, las ciudades de la zona fronteriza mexicana experimentaron un gran crecimiento que han mantenido hasta el presente. Tijuana, Mexicali, Ciudad Juárez, Reynosa, Nuevo Laredo y Matamoros se convirtieron en centros de servicios, de comercio, y diversión para millones de soldados estadounidenses apostados en varias bases militares en Texas y el suroeste. Las economías de todas estas poblaciones, especialmente en lo referente a la agricultura y la ganadería, se robustecieron debido al aumento en las exportaciones mexicanas a Estados Unidos a raíz de las necesidades materiales de los países aliados. Migrantes del centro y sur de México se mudaron al norte en busca de empleo. El gobierno mexicano estableció políticas de apoyo para los pequeños propietarios, invirtió cuantiosas sumas de dinero en obras de riego (sobre todo en el norte y el noroeste), amplió los sistemas de crédito agrícola, y expandió las redes existentes de energía eléctrica y de carreteras. Esta combinación de circunstancias condujo a una rápida urbanización en los estados fronterizos, con un marcado crecimiento poblacional en algunas ciudades como Hermosillo, Ciudad Obregón, Guaymas, Culiacán, Torreón, Mexicali y Matamoros (Unikel, et al., 1978:39 y 42).

De 1940 a 1980, la población de los estados fronterizos mexicanos del norte se cuadruplicó de 2.6 millones a casi 10.7 millones de habitantes. El incremento fue especialmente rápido durante los años de 1940 a 1960, cuando la población de los estados fronterizos creció un 91 por ciento, mientras que la del país en general sólo subió un 67 por ciento. También durante este mismo período ocurrió una redistribución de la población en el interior de la zona fronteriza. Baja California y Sonora constantemente adquirieron habitantes, mientras que Chihuahua, Coahuila, Nuevo León y Tamaulipas experimentaron reducciones en su peso porcentual. La población no nativa (o inmigrante) que residía en los estados fronterizos casi se quintuplicó, de alrededor de 530,000 a 2.5 millones.

Con excepción de la década de 1960 a 1970, el factor principal en el incremento poblacional de la región, particularmente referente a Baja California y Sonora, fue la inmigración de mexicanos del centro y sur del país. Durante este período, de esta población inmigrante, un creciente porcentaje eligió asentarse en Baja California y Sonora, y de preferencia en Chihuahua, Coahuila, Nuevo León y Tamaulipas. La población total de los 36 municipios a lo largo de la frontera aumentó de 383,000 en 1940 a 2.95 millones en 1980. Esta última cifra abarcaba el 75 por ciento de la población de los estados fronterizos (Estrella, 1987:391-395; Ham, 1987:9-10). 
A raíz de la intensificación de la migración de trabajadores mexicanos a Estados Unidos, algunas ciudades fronterizas tuvieron altos índices de crecimiento. La población de Tijuana, por ejemplo, subió de 60,000 habitantes aproximadamente en 1950 a más de 276,000 en 1970, mientras que la de Ciudad Juárez creció de 122,000 a 414,000 para los mismos años. Mexicali, Nogales, Nuevo Laredo, Reynosa y Matamoros también experimentaron grandes incrementos (ver figura 5). No todo este aumento se debió a la inmigración desde el interior del país; una parte fue resultado de disminuciones en las tasas de mortalidad a raíz de mejoras en los programas de salud pública, así como la permanencia de altas tasas de fecundidad (Florescano, 1983:160; Ham, 1987:9-10).

Además, hubo una creciente concentración de la población de los estados fronterizos en estos municipios, del $14.6 \%$ en 1940 al $27.6 \%$ en 1980. Coahuila, Nuevo León y Tamaulipas redujeron su participación en el total de población de la franja fronteriza, del $47.9 \%$ al $34.1 \%$ de 1940 a 1980; Chihuahua también disminuyó su peso porcentual, del 22.0 al 21.4 por ciento; en cambio, Baja California y Sonora incrementaron su participación del 30.1 al 44.5 por ciento. Como en el caso referente al incremento poblacional de los estados fronterizos en general, este fenómeno se debió al flujo de inmigrantes (de 143,000 en 1940 a 1'033,000 en 1980). Por otra parte, al igual que el caso de la población en su totalidad, un creciente porcentaje de los inmigrantes se asentaban en los municipios fronterizos de Baja California y Sonora (Unikel, et al., 1978:78; Estrella, 1987:395).

De 1960 a 1980, las ciudades de la frontera norte perdieron gran parte de su atracción poblacional (aunque hubo un aumento en la población flotante debido a la migración ilegal). Con el desarrollo de la industria de las maquiladoras en la década de 1980, empero, el crecimiento de la población de las ciudades fronterizas recibió un fuerte estímulo. Chihuahua, Ciudad Juárez y Tijuana alcanzaron poblaciones de entre medio y un millón de habitantes (ver figura 6) (Unikel, et al. 1978:60).

De 1970 a 1980, el ritmo de crecimiento de la población nativa de los municipios fronterizos fue inferior a la tasa de crecimiento del total de la población del país (considerada como tasa de crecimiento natural). Durante esta década, la magnitud de la inmigración tendió a reducirse; además, a diferencia de lo que tradicionalmente había acontecido, las entidades de la frontera norte del país aportaban población en los flujos de inmigración de emigrantes indocumentados que se internaban a Estados Unidos en busca de empleo. Esta ola de migrantes consistía no sólo en aquellos mexicanos que a su vez habían inmigrado a esas entidades, sino también incluía a residentes nativos de los propios estados de la frontera norte (Estrella, 1987:396-397). 


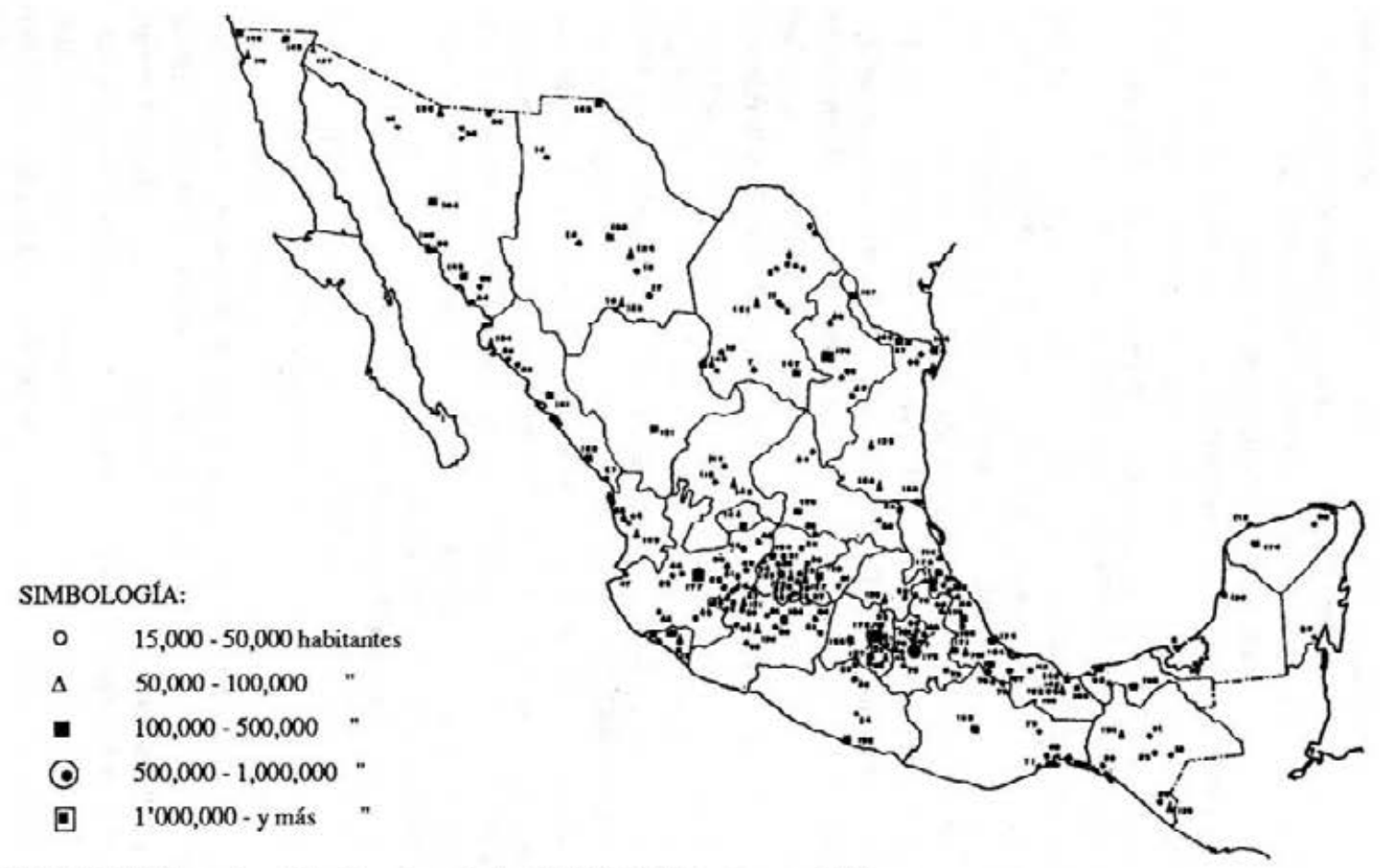

FIGURA 5. México: localidades de más de 15,000 habitantes en 1970.

FUENTE: Unikel, el al. El desarrollo urbano de México: diagnóstico e implicaciones futuras (1970:40). 


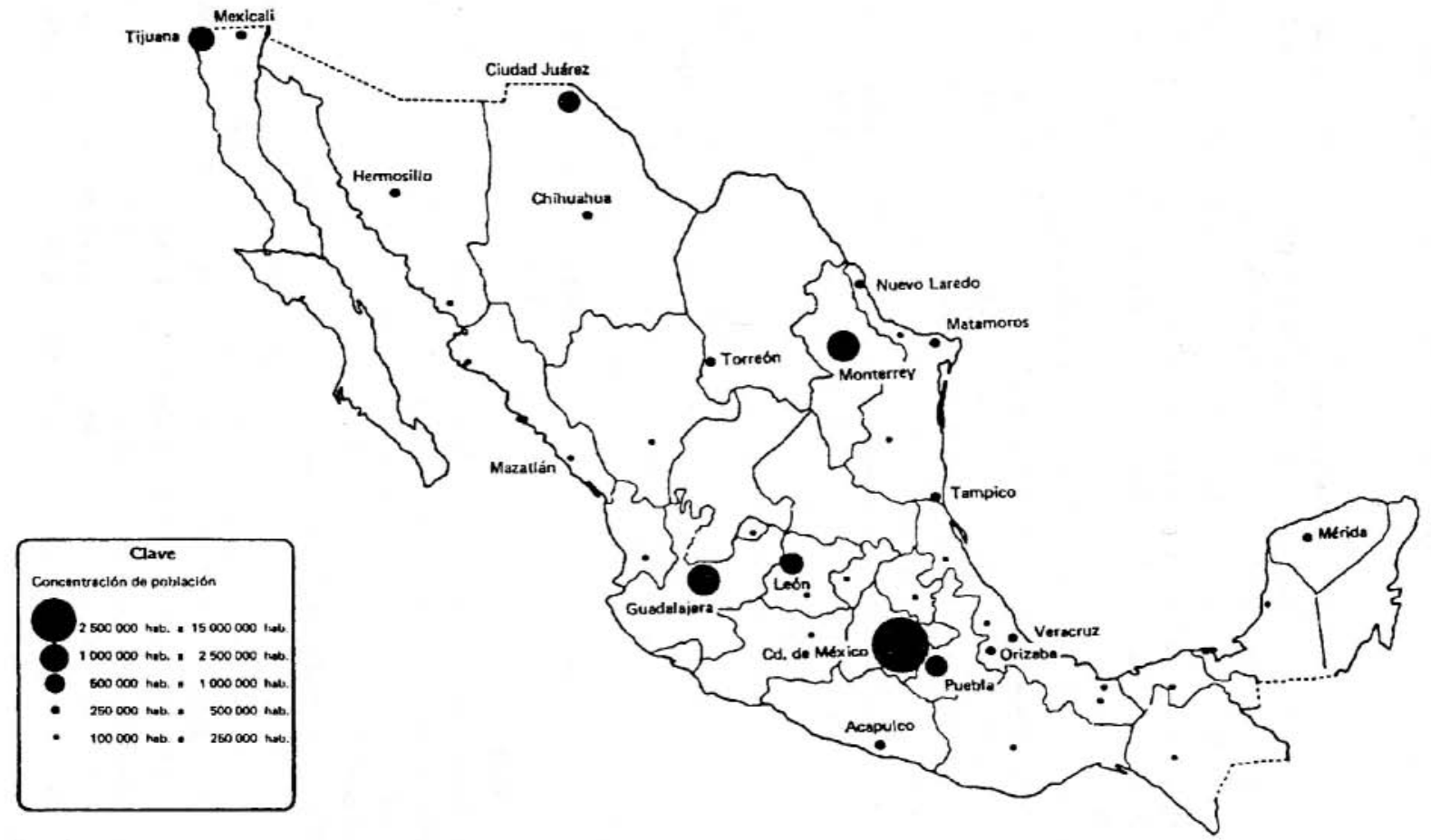

FIGURA 6.

FUENTE: Enrique Florescano, (coord.) Atlas Histórico de México (1983:217). 


\section{EL ALTO ÍNDICE DE URBANIZACIÓN DE LA POBLACIÓN FRONTERIZA}

Una de las características poblacionales de los cstados fronterizos más notables del último medio siglo radica $\mathrm{en} \mathrm{el} \mathrm{hecho} \mathrm{de} \mathrm{que} \mathrm{la} \mathrm{proporción}$ urbana-rural es cada vez mayor; mientras que en 1940, el 71 por ciento de la gente era rural y el 29 por ciento urbana, para 1980, había sido invertida casi por completo esta tendencia, con 30 por ciento rural y 70 por ciento urbana. Además, durante el mismo período, los habitantes de los estados se concentraron cada vez más en las poblaciones ubicadas en la línea divisoria; en 1940, los municipios de la frontera contaban con 383,000 habitantes, mientras que para la década de los ochenta, oscilaban entre los tres y cuatro millones. Este fenómeno sigue vigente en la actualidad, puesto que el 80 por ciento de los habitantes de las poblaciones fronterizas residen en localidades de más de 100 mil habitantes, siendo las más importantes Tijuana, Mexicali, Nogales, Ciudad Juárez, Piedras Negras, Ciudad Acuña, Nuevo Laredo, Reynosa y Matamoros (Pinera, 1987, V.3:459).

La urbanización del noroeste durante el período de 1940 a 1970 fue estimulada por los siguientes factores: a) fuertes inversiones en obras de riego por parte del sector público; b) la formación de un sector privado agrícola moderno en Baja California, Sonora y Sinaloa; c) el crecimiento de los servicios en las ciudades fronterizas con Estados Unidos; y d) un período de auge agrícola durante la segunda guerra mundial y la década de los cincuenta. Hay que señalar, empero, que algunas de estas condiciones favorables no tuvieron el mismo impacto sobre el proceso de urbanización en otras entidades de la frontera norte.

La acelerada urbanización del noroeste y de Tamaulipas se caracteriza por una fuerte atracción de población de otras regiones que se refugian esencialmente en el sector urbano y, en menor grado, en el rural, debido fundamentalmente, en el caso del noroeste, a la utilización de grandes extensiones de tierra en los estados de Sinaloa y Sonora, gracias a las muchas obras de infraestructura realizadas por el gobierno federal, $y$ a su utilización en productos agropecuarios de gran demanda internacional - ganado, algodón, tomate, etc.- en modernas granjas con una eficiente organización comercial. El estado de Baja California ha tenido un crecimiento muy dinámico debido al desarrollo del sector agrícola, así como de actividades comerciales y turísticas con el estado de California. Tamaulipas también ha experimentado notables avances en la aplicación de sistemas y técnicas de la agricultura moderna.

A pesar de que algunos centros urbanos de la región fronteriza siguen experimentando grandes incrementos en términos de gente, el territorio en 
general continúa presentando las más bajas densidades de población del pais (Unikel, et al. 1978:68, 73-74, 78 y 90). En el futuro podrá absorber únicamente un flujo limitado de inmigrantes, puesto que el obstáculo principal al crecimiento de población en el norte de México se debe a que en grandes áreas de la zona existen escasos acuíferos subterráneos con profundidades próximas a la superficie (CONAPO, $s / \mathrm{f}$ ).

\section{LA POBLACIÓN DE ORIGEN MEXICANO EN EL SUROESTE DE ESTADOS UNIDOS}

La población fronteriza de los estados de Texas, Nuevo México, Arizona y California está conformada en gran parte por personas de origen mexicano, independientemente de que éstos hayan nacido en Estados Unidos o sean naturalizados. En la actualidad viven aproximadamente diez millones de méxico-americanos en los estados del suroeste, alrededor del 80 por ciento de los cuales radican a menos de 400 kilómetros de la frontera con México. Además de constituir uno de los más grandes e importantes grupos étnicos en Estados Unidos, la población mexico-estadounidense recibe constantemente, a través de la inmigración, grandes agregaciones de personas para aumentar aún más este número.

Después del fin de la guerra México-Estados Unidos, se quedaron cntre 75,000 y 85,000 mexicanos en el territorio conquistado, o sea, 1.6 por ciento de la antigua población de México que ocupaba un 51 por ciento de las tierras que anteriormente habían pertenecido a ese país (véase figura 7). Entre 60,000 y 65,000 vivían en el territorio de Nuevo México, que entonces abarcaba Arizona y una porción de Colorado. También había entre 10,000 y 12,000 en California (de una población total de casi 100,000), así como entre 5,000 y 8,000 en Texas.

De 1848 hasta finales del siglo XIX, el crecimiento de la población méxico-norteamericana, al igual que de su contraparte mexicana al otro lado de la frontera, fue lento. Relativamente, pocos mexicanos inmigraron a Estados Unidos durante este período.

En Nuevo México, los hispanoparlantes se encontraban concentrados a lo largo del valle del río Bravo al norte de El Paso del Norte (las actuales ciudades de Ciudad Juárez y El Paso). Los asentamientos mexicanos en California estaban distribuidos por toda la costa, desde San Diego en el sur hasta la bahía de San Francisco en el norte. En Texas, los mexicanos residían principalmente en el valle del bajo río Bravo, en San Antonio y sus alrededores, Goliad, y Victoria, el área de Nacogdoches y cerca de la actual ciudad de El Paso. Enel sur de loque hoy en día es Arizona, los pueblosmexicanos más importantes eran Tucson y Tubac, con algunos pequeños asentamientos en otros lugares. ${ }^{3}$ 
En opinión de diversos analistas, la recesión estadounidense y la presión electoral en ese país pusieron de nueva cuenta a la industria petrolera mexicana en la mesa de negociaciones a principios de 1992.

"Si se quiere que el tratado se firme antes de las elecciones, México tendría que ofrecer al gobierno estadounidense concesiones importantes, entre ellas la apertura de la industria petrolera a la inversión extranjera, para ofrecer un acuerdo vendible", declaraba a principios de 1992 Abel Beltrán del Río, presidente de la consultoría Ciemex-Wharton (El Financiero, 28 de agosto de 1991).

Por su parte, el secretario de comercio de México señaló en enero, que en el TLC hay un capítulo dedicado a la energía, "en que se analizan los flujos comerciales", pero aclaro que "ninguna de las restricciones constitucionales en la materia serian sujetas a negociación".

El jefe de la oficina negociadora, Herminio Blanco, entrevistado en esa ocasión, decía que "en el capítulo sobre energéticos se está viendo todo lo relacionado con importaciones y exportaciones". "¿De petrolíferos?", se le preguntó, y su respuesta fue: "es todo lo que puedo decir" (El Financiero, 23 de enero de 1992).

La representante comercial estadounidense Carla Hills, declaró a periodistas en Washington que si bien se respetarian las restricciones constitucionales mexicanas respecto a hidrocarburos, "la energía es un punto muy importante para nuestra economía y hemos estado discutiendo el tema con ese país". No es difícil suponer que en febrero el tema continuó en la mesa de discusiones. Los secretarios de comercio de México, Canadá, y la representante comercial estadounidense, sostuvieron reunión privada ese mes en Maryland, "para revisar avances en la negociación y destrabar nudos de conflicto" (El Financiero, 23 de enero de 1992).

En julio de 1992, fuentes oficiales informan que en el contexto del tratado, el gobierno mexicano permitiría la importación de gasolina y diesel de Estados Unidos y Canadá; de acuierdo con ello, se reformaría la Ley del Impuesto sobre Producción y Servicios (El Financiero, 10 de julio de 1992).

Grupos negociadores del Tratado Norteamericano de Libre Comercio continuaron en agosto con la redacción de textos de los 18 temas, sin incluir aún energía, en la expectativa de terminarlos en las semanas siguientes. Mientras tanto, en Washington, seguían los trabajos en torno al sector automotriz, energía y compras gubernamentales (El Financiero, 6 de agosto de 1992b).

Durante los trabajos de la VII reunión ministerial en Washington - la más prolongada de todas - los ministros de comercio mexicano y canadiense, así como la representante comercial de Estados Unidos, no habfan 
podido superar el escollo representado por el sector energético, pues los últimos persistieron en la demanda de que México liberase el petróleo y asegurara el abasto de crudo.

Fuentes allegadas comentaron: "del puñado de temas sobre los que concentran tiempo y esfuerzo Hills, Serra Puche y Wilson, la apertura de Petróleos Mexicanos a compañías estadounidenses y canadienses proveedoras de equipo y servicios petroleros ha convertido la mesa de compras gubernamentales en una verdadera arena de boxeopolítico" (El Financiero, 11 de agosto de 1992).

La propuesta de México de reservar a la industria mexicana $80 \%$ de las compras que efectúe Pemex y Comisión Federal de Electricidad (CFE), se modificó a 55\% durante los primeros ocho ańos del TLC, al cabo de los cuales bajará a $30 \%$. La propuesta de México consideraba que las empresas mexicanas mantuvieran el derecho a competir en la porción de los contratos abiertos a licitación extranjera. Sin embargo, Estados Unidos insistió en que México reservara $30 \%$ a su industria, llegando a ese porcentaje en tres años. Además, Estados Unidos demandó que la empresa mexicana no participe en el $70 \%$ restante.

Estados Unidos tampoco pareció quitar el dedo del renglón en lo referente a seguridad de abasto petrolero en tiempos de crisis. Personas cercanas a las pláticas dijeron que los negociadores canadienses volvieron a amenazar con que si México no cede en esto, Canadá renunciará a la cláusula de abasto seguro en el convenio bilateral con Estados Unidos, medida considerada por muchos canadienses como entrega de soberanía.

Según fuentes oficiales en Washington, a fines de agosto de 1992, cuando los negociadores de los tres gobiernos daban toques finales al compacto trilateral, "en materia de energéticos se habrían superado los obstáculos con estricto apego a la Constitución Mexicana" (El Financiero, 12 de agosto de 1992).

La primera impresión del proceso fue que los negociadores mexicanos habrían defendido la soberanía actuando con apego estricto al documento constitucional. Sin embargo, un común denominador en el manejo de información hacia la opinión pública fue la ausencia de detalles y la vaguedad reiterada en el tema de energía. Se omitió lo sustancial en un asunto de gran importancia. Los negociadores pretendieron implicar la cuestión del abasto seguro con restricciones constitucionales, siendo más bien un asunto de intercambio comercial, que no guarda relación alguna con la Constitución Mexicana.

Si bien México no se obligó a asegurar el abasto estratégico, sí suscribe un compromiso moral de ofrecerlo a Estados Unidos antes que 
Sin embargo, a partir de la década de 1880 , la población mexicana empezó a incrementarse notablemente debido a una inmigración importante proveniente de Sonora para trabajar en las minas de cobre en el sur de Arizona, en los ferrocarriles y en los grandes proyectos de reclamación de tierras. El censo de 1880 reportó que había 9,330 mexicanos en el territorio; para 1900, existían 11,544, y, una década después, el número había crecido a 29,452 (McWilliams, 1979:91; Acuña, 1976: 123-124).

Texas, por su parte, recibió la mayoría de los inmigrantes mexicanos. Para 1880, el número de mexicanos se había incrementado a aproximadamente 50,000 y, en 1910, había alcanzado la cifra de 100,000 , es decir, el doble. Aunque una porción del aumento se debió al crecimiento natural de la población, la mayor parte del incremento fue resultado de la inmigración (McWilliams, 1979:94).

Cabe notar que, referente a las cifras de la población de ascendencia mexicana durante la segunda mitad del siglo XIX, los censos no son muy precisos. En general, faltaban empleados y supervisores para llevar a cabo las encuestas. Los comisarios de los diferentes distritos, que no estaban bajo la jurisdicción de la Oficina del Censo, tenían la tarea de contar a la gente; éstos, a su vez, designaron a sus propios ayudantes y no existía ningún aparato administrativo para supervisar el trabajo de ambos. No había una adecuada distribución de los encuestadores, puesto que los distritos más poblados contaban con $\mathrm{cl}$ mismo número de entrevistadores que los que tenían menos gente. Los comisarios fueron auxiliados por efectivos del ejército, quienes, durante sus ratos de ocio, llevaban a cabo el censo en los territorios y distritos de escasa población. Muchas personas, temerosas y sospechosas del propósito del conteo, se escondieron o no proporcionaron respuestas muy honestas o completas. No había ninguna uniformidad entre las fechas del comienzo y terminación del censo; tampoco existía algún procedimiento para tratar lo referente a población "flotante". Era difícil alcanzar a la gente que vivía en áreas aisladas, como en las regiones montañosas, $\mathrm{y}$, a menudo, no se contaba a los niños de menos de cinco años. Había errores de tipo humano en casi todas las etapas del proceso de captura y procesamiento de la información.

También existían problemas de tipo racial o étnico. Para el censo, los mexicanos deberían de ser contados como "blancos", pero, dado que una proporción significativa de la población mexicana tenía rasgos indígenas, probablemente varios no fueron contados tampoco al censar a los indios (de los cuales había aproximadamente 250,000 en 1848) y viceversa; algunos, sin duda, fueron clasificados como parte de la población nativa cuando se empezó el proceso de contar a los indigenas. Respecto al lugar de nacimiento, debido al grado de discriminación característica de la 
época, probablemente muchos de los que nacieron en México intentaron mostrar que habían nacido en Estados Unidos.

Algo semejante ocurría con respecto a los apellidos. Varias personas con apellidos extranjeros los cambiaron al inglés para ser aceptados por la sociedad en general. Además, más mujeres que hombres de origen mexicano se habían casado con personas de la población anglosajona, y, como consecuencia, sus apellidos habían cambiado. Por ende, cualquier conteo que tomara en cuenta los apellidos de las personas produciría inevitablemente una cifra más reducida de la que había en realidad (Acuña, 1976:167; Martínez J., 1975:47-48).

Antes de 1900, relativamente pocos mexicanos emigraron a Estados Unidos. La mayoría de ellos se asentaron en los estados del suroeste, distribuidos de la siguiente manera: en Texas, 71,062; Arizona, 14,172; California, 8,096; y Nuevo México, 6,649 (McWilliams, 1979:193).

La población méxico-norteamericana empezó a crecer a un ritmo acelerado durante el medio siglo después de 1900. Durante la década de 1900 a 1910, la población de origen mexicano se duplicó de poco más de 100,000 a más de 200,000 . El cuadro 1 y la figura $8^{4}$ muestran el incremento poblacional para las décadas de 1880 a 1910 :

De 1910 a 1920, el grupo inmigrante se cuadruplicó, debido en gran parte al estallido de la revolución mexicana, que causó que miles de refugiados se trasladaran a Estados Unidos, donde se asentaron principalmente en las poblaciones fronterizas más grandes como El Paso y Laredo.

No sólo se incrementó en gran escala el número de inmigrantes mexicanos a Estados Unidos, sino que también su carácter y trayectoria empezaron a cambiar. Hasta 1910, la mayoría de los inmigrantes mexicanos en Estados Unidos provenían del norte de México. Después de esta fecha, comenzaron a emigrar personas de los estados del interior de la república, como Guanajuato, Jalisco, México y otros, debido en parte a las presiones demográficas existentes en aquellas regiones y también a la condición debilitada de la economía en los sectores rurales y urbanos a raíz de las luchas revolucionarias (González, 1960:124 y 135; INEGI, 1985:3). Aunque Texas continuó siendo el destino de la mayoría de los inmigrantes mexicanos, se incrementó la corriente migratoria a California, Colorado y, en forma limitada, a los estados del lejano noroeste (Oregon y Washington) (Slatta, 1975:328-329). De 1920 a 1929, la tasa media anual de incremento de la población de origen mexicano en California fue de 20.4 por ciento y

4 Tomada de Moisés González Navarro, La Colonización en México, 1877.1910 (1960:123). 
CUADRO 1. Incremento poblacional para las décadas de 18801910.

\begin{tabular}{cc}
\hline Año & Número de personas \\
\hline 1880 & 68399 \\
1890 & 77853 \\
1900 & 103393 \\
1910 & 221915 \\
\hline FUENTE: Moisés González Navarro, La Colonización en México 1877-1910 (1960).
\end{tabular}

en Colorado de 30.2 por ciento; en cambio, la de Texas y Nuevo México fue de 7.6 por ciento, mientras que en Arizona se registró un leve incremento durante este período (Hernández, 1967:19).

La población de origen mexicano también comenzó a desplazarse rumbo al noreste hacia Michigan. El número de mexicanos en Kansas, por

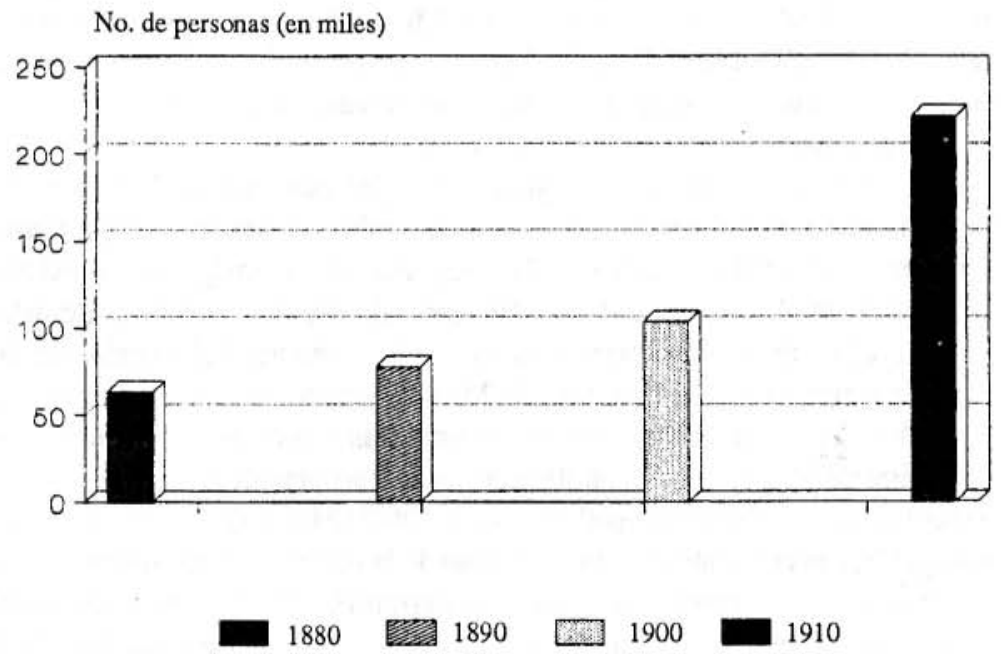

FIGURA 8. Incremento poblacional para las décadas de 1880-1910. FUENTE: Moisés González Navarro, La Colonización en México 1877-1910 (1960). 
ejemplo, subió de 71 en 1900 a 8,429 en 1910. Los mexicanos se asentaron a lo largo de la ruta de migración hacia el noreste, en las regiones donde había más oferta de empleo, principalmente las industrias manufactureras que surgían en Chicago, Gary y Detroit (González, 1960:126; Acuña, 1976:168).

A raíz del decrecimiento de la producción agrícola en México, durante la década de 1920 a 1930, miles de campesinos mexicanos emigraron a Estados Unidos. En las áreas rurales de los estados anteriormente mencionados, los mexicanos encontraron empleo en el cultivo de la remolacha azucarera y en la construcción, reparación y mantenimiento de los ferrocarriles. Hubo otros factores que promovieron la inmigración mexicana durante este período. Al entrar México a una etapa de reconstrucción después de la lucha armada de la década anterior, el renovado sistema ferroviario, junto con la gran expansión de la red estadounidense, facilitó el movimiento de los mexicanos hacia el norte y a lo largo de la frontera. La política económica de Estados Unidos también favoreció a varios miles de mexicanos quienes acudieron a las ciudades fronterizas que se convirtieron en centros de contratación para el reclutamiento, tanto legal como ilegal, de trabajadores para las empresas agrícolas y las grandes corporaciones. De 1925 a 1929, un total de 238,527 mexicanos entraron a Estados Unidos (Acuña, 1976:179).

Durante las tres primeras décadas del sigloXX, es decir, de 1900 a 1930 , más de un millón de inmigrantes mexicanos llegaron a Estados Unidos, cuyo desplazamiento en los diferentes estados fronterizos se indica en el cuadro 2 y la figura 9.

CUADRO 2. Inmigrantes mexicanos en los estados fronterizos de Estados Unidos.

\begin{tabular}{lrrrr}
\hline Estado & 1900 & 1910 & 1920 & 1930 \\
\hline Arizona & 14171 & 29987 & 61580 & 114173 \\
California & 8086 & 33694 & 88881 & 368013 \\
Nuevo México & 6649 & 11918 & 20272 & 59340 \\
Texas & 71062 & 125016 & 251827 & 683681 \\
\hline
\end{tabular}

FUENTE: Elaborado por el autor. 


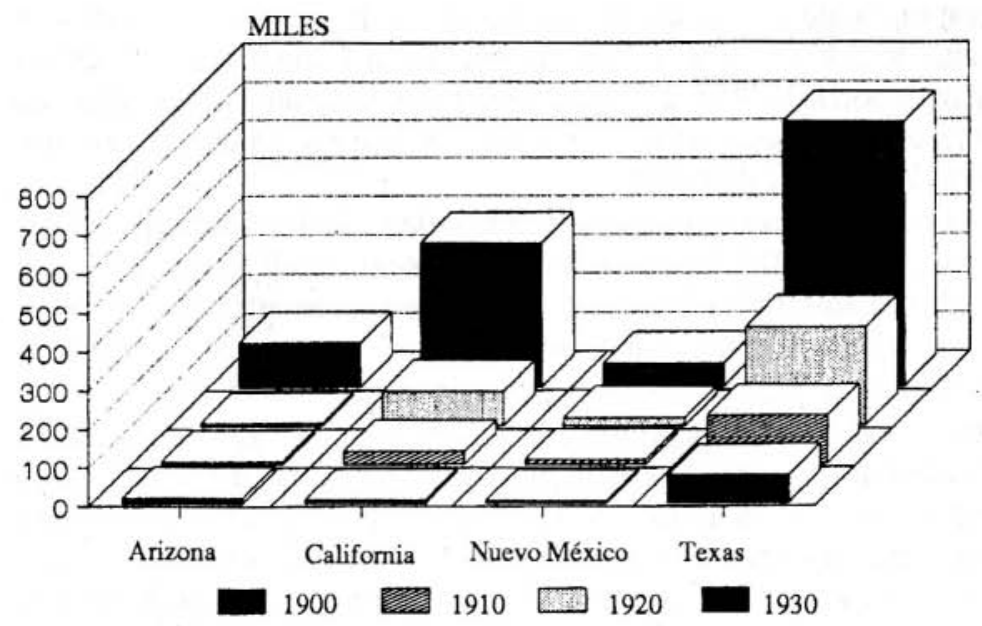

FIGURA 9. Inmigrantes mexicanos en los estados fronterizos de Estados Unidos.

FUENTE:Elaborado por el autor.

Noventa por ciento de estos inmigrantes se asentaron en los estados fronterizos de Estados Unidos; este porcentaje quedaría vigente aproximadamente hasta 1950, cuando empezaron a cobrar importancia los nuevos patrones de asentamiento indicados previamente. Para 1930, la población de origen mexicano había alcanzado la cifra de alrededor de un millón y medio de personas (McWilliams, 1979:55 y 193-194; Hernández, 1967:19).

Debido a la contracción en general de la economía mundial después de la crisis de 1929, un gran número de mexicanos que habían sido contratados por diferentes empresas fueron despedidos. También hubo menor demanda de la mano de obra mexicana en el campo, debido a innovaciones mecánicas en la agricultura. El número de inmigrantes mexicanos se redujo hasta el punto de casi cesar completamente: de 1930 a 1934, fue de 19,200, y de 1935 a 1939, de 8,737 (Carreras, 1974:57-70; Acuña, 1976:179).

La crisis produjo un sentimiento antimexicano entre los angloestadounidenses, quienes acusaron a los mexicanos de quitarles empleos que deberían pertenecerles a ellos. Este sentimiento resultó en una campaña de repatriación que afectó no sólo a los mexicanos recién llegados, sino también a los nacidos en Estados Unidos. Alrededor de medio millón de mexicanos fueron repatriados de manera forzosa, mientras que otros miles 
regresaron voluntariamente. La población mexicana en Estados Unidos en general declinó de modo significativo en este período (Carreras, 1974: 173-176; Pif̃era, 1987 V. 3: 167-168; López, 1979:56).

La deportación masiva de los mexicanos durante la década de 1930 a 1940 enfatizó la naturaleza esencialmente cíclica del patrón que gobernaba la emigración de obreros mexicanos al país del norte en este período y que serviría como pauta durante las décadas subsecuentes. El Departamento de Inmigración de Estados Unidos abría las puertas a la inmigración de trabajadores mexicanos durante períodos de escasez de mano de obra, seguido por políticas restrictivas y hasta deportaciones masivas durante épocas de recesión económica. De 1880 a 1929, cuando los obreros mexicanos empezaron a entrar a Estados Unidos en números significativos, la política migratoria de este país era relativamente sin restricciones. Hay que sefialar que, en algunas $\propto$ casiones, se limitó la libre entrada de los trabajadores mexicanos, porque su competencia perjudicaba a los estadounidenses. Por añadidura, algunos braceros se vieron obligados a regresar a México debido a la paralización temporal (a veces) de los trabajos ferroviarios y mineros (González, 1960:125).

Durante la segunda guerra mundial, se presentó otra escasez de mano de obra en Estados Unidos, particularmente en la agricultura, que todavía estaba (en general) en un cstado incipiente de mecanización. En 1942, los gobiemos de México y Estados Unidos concretaron un sistema de trabajo por contrato, el llamado programa de braceros, que duró hasta 1964. La demanda de mano de obra mexicana continuó durante los prósperos años del período de posguerra de 1950 a 1970. Este factor, junto con la explosión demográfica en México y la falta de oferta de empleoen este país, estimuló la migración de millones de inmigrantes, legales e ilegales, a Estados Unidos. De 1'861,400 personas en 1940, la cifra de población de origen mexicano ascendió a más de 4'500,000 en 1970. Para esta última fecha, alrededor de 75 por ciento de esta población vivía en los estados de Texas y California, como se muestra en el cuadro 3 y la figura 10, que indican el aumento poblacional entre 1950 y $1970 .^{5}$

Para 1980, según el censo de aquel año, existían alrededor de 8.5 millones de estadounidenses de origen mexicano (Ortega, 1987:11; De Ley, 1987:26). La población méxico-cstadounidense crece a un ritmo más acelerado que el de otros grupos étnicos, dado que existen proporcionalmente más jóvenes que en el caso de los grupos no hispanos. Además, las tasas de nacimiento de los hispanoparlantes e indios del suroeste son más

5 Datos tomados de David R. Maciel y José Carlos Romero (véase también: 1987, Vol. 3: 473; Bean, et al., 1987: 19-20; Burma, 1974: 5 y 36; Marínez, 1982: 150-151 y 197). 
altas que cualquier otro grupo étnico de la región. Asimismo, la mortalidad infantil disminuye en estos grupos. Por ejemplo, entre 1929 y 1944, la tasa decreció en Nuevo México de 145.5 muertes infantiles por 1,000 nacimientos, a 89.1. Sin embargo, el aumento de la población de origen mexicano, en la actualidad, se debe sobre todo a la inmigración procedente de México, que es un fenómeno constante. Al presente ritmo de crecimiento, para finales de este siglo, la población de origen mexicano constituirá la minoría más significativa en Estados Unidos, en términos de números, incrementando al mismo tiempo su poder dentro del gobierno de dicho país.

CUADRO 3. Aumento de población de origen mexicano en los estados fronterizos de Estados Unidos (1950-1970).

\begin{tabular}{lrrr}
\hline & \multicolumn{3}{c}{ Número de personas (en millares) } \\
Región & 1950 & 1960 & 1970 \\
\hline Suroeste & 2290 & 3465 & 4668 \\
California & 760 & 1427 & 2222 \\
Texas & 1034 & 1418 & 1663 \\
Nuevo México & 249 & 269 & 324 \\
Arizona & 128 & 194 & 246 \\
Colorado & 118 & 157 & 212 \\
\hline
\end{tabular}

FUENTE: Datos tomados de David R. Maciel y José Carlos Romero (1987).

En la actualidad, de los aproximadamente diez millones de méxiconorteamericanos que habitan los estados fronterizos de Estados Unidos, una cuarta parte de las personas de origen mexicano de 20 años que radican en aquel país no nacieron allí; otro $41.9 \%$ son hijos de padres o madres nacidos en México. Cerca del $71 \%$ de la población méxico-norteamericana adulta, consiste en inmigrantes recientes y sus parientes. Si bien la población de origen mexicano tiene ingresos y niveles educativos sumamente bajos no sólo en la primera generación sino hasta en la segunda y tercera, por lo menos algunos han podido superarse en términos de educación, ocupaciones laborales y salarios. Por añadidura, existen probablemente entre tres y seis millones de ilegales residentes en Estados Unidos, la mitad de los cuales son mexicanos (McWilliams, 1979:352; Maciel, et al., 1987:473-474; Ortega, 1987:11-12). 


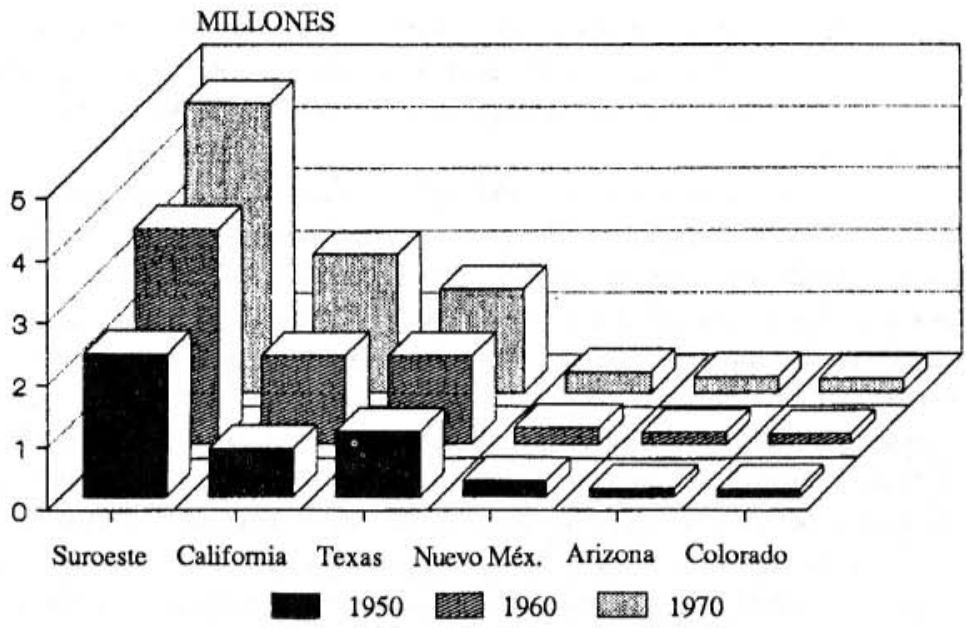

FIGURA 10. Aumento de población de origen mexicano en los estados fronterizos de Estados Unidos (1950-1970).

FUENTE:Datos tomados de David R. Maciel y José Carlos Romero (1987).

\section{URBANIZACIÓN DE LA POBLACIÓN MÉXICO-NORTEAME- RICANA}

Aunque entre el 82 y $85 \%$ de los mexicanos en Estados Unidos siguen siendo residentes del suroeste, desde principios del siglo, como en el caso del resto de la población estadounidense, la comunidad méxico-norteamericana se ha urbanizado cada vez más. Los inmigrantes que llegaron entre 1900 y 1930 se establecieron crecientemente en las áreas urbanas, debido a que la mecanización de la producción de algodón y la de varios tipos de frutas y verduras redujo la oferta de trabajo en este renglón. Hacia 1930, el $57 \%$ del total nacional de estos inmigrantes eligieron vivir en las ciudades. No obstante, durante este mismo período, el sector rural todavía absorbía un buen porcentaje de los inmigrantes, sobre todo los braceros; de hecho, hasta bien entrado este siglo, los méxico-norteamericanos constituyeron el 80 por ciento de la fuerza laboral agrícola en el suroeste.

El proceso de urbanización entre la población de origen mexicano se aceleró entre 1930 y 1950, alcanzando su apogeo durante la segunda guerra mundial y a principios de los años de posguerra. Para 1950, más del $70 \%$ de los integrantes de este grupo y sus hijos pertenecieron al sector urbano. Actualmente, los méxico-norteamericanos representan una población 
principalmente urbana, aun cuando los mexicanos siguen constituyendo una alta proporción de obreros permanentes y de temporada en la agricultura (McWilliams, 1979: 58; Ortega, 1987: 12; Bean y Tienda, 1987: 3, $19-20$ y 22$)^{6}$

En resumen, el gran crecimiento de la población de origen mexicano en Estados Unidos durante este siglo ha sido producto en gran medida de la inmigración, más que del incremento natural de la original población hispana del suroeste. Esta inmigración se remonta al período cuando se estableció la frontera en 1848, con los movimientos de personas del noroeste y otros lados de México a California durante la fiebre de oro. En cuanto a las regiones de asentamiento de mexicanos en territorio estadounidense, se puede ver que originalmente la mayor parte de la población méxico-norteamericana estaba concentrada en el entonces territorio de Nuevo México, pero, para principios de este siglo, con el incremento sustancial en la inmigración de mexicanos, los estados de Texas y California se convirtieron en los polos de atracción poblacional. Aunque este patrón sigue vigente en la actualidad, la población de origen mexicano se restringe cada vez menos a su viejo dominio del suroeste; más bien, se está extendiendo por casi todas las regiones de Estados Unidos.

Por último, cabe señalar que, a lo largo del casi siglo y medio que ha transcurrido desde la creación de la frontera en 1848, el movimiento de mexicanos a través de la frontera no ha sido en una sola dirección, es decir, de México a Estados Unidos, sino que también hubo un movimiento, si bien limitado, de mexicanos en dirección contraria durante este periodo. Esta migración ocurrió en conexión con los intentos por parte del gobiemo mexicano de repatriar a los mexicanos que se habian quedado del lado estadounidense de la frontera al firmarse el tratado de Guadalupe Hidalgo, sus descendientes, o mexicanos que se encontraran sin emplco en Estados Unidos.

Durante el año subsiguiente a la firma del tratado, alrededor de 3,000 personas aceptaron la oferta del gobiemo mexicano para costear su viaje a México y radicar allí (McWilliams, 1979:10; Martínez, 1975:50-51). ${ }^{7}$ Aunque los proyectos de repatriación cesaron durante las guerras de reforma y de la intervención francesa debido a los trastornos provocados por estas luchas, se reiniciaron con vigor durante el período de gobierno del presidente Díaz. La Ley sobre Colonización y Baldíos de 1883 ofreció

\footnotetext{
6 En el sudoeste, la urbanización de los méxico-norteamericanos ha sido incluso más acentuada que la de los angloestadounidenses (para mayores detalles véase David R. Maciel y José Carlos Romero, 1987:474).

MoWilliams presenta una cifra de entre 1,500 y 2,000 , pero he tomado la estimación de Martínez como la más confiable, puesto que su análisis de los movimientos de mexicanos en la región en los años subsecuentes a la guerra es mucho más detallado.
} 
a los mexicanos residentes en el extranjero dispuestos a establecerse en las regiones desérticas del norte de México, 200 hectáreas y quince años de las exenciones otorgadas en ellas. Durante este mismo período, el desarrollo de la minería y de los ferrocarriles en los estados fronterizos, especialmente en Sonora, fue muy atrayente para muchos mexicanos radicados en Estados Unidos. Sin embargo, los intentos fracasaron (en general) a raíz de la falta de recursos y de apoyo financiero por parte del gobierno porfirista, mientras que los proyectos exitosos resultaron en la introducción de menos de mil repatriados a México (González, 1960:6, 95 y 118-123; Carreras, 1974: 43-45; Cortés, 1979; 4-12).

Durante la lucha armada de 1910 a 1920, los gobiernos de Madero, Huerta, Carranza y de la Huerta también emprendieron proyectos de colonización, logrando establecer en México a centenares de individuos y familias enteras en Coahuila y otros estados de la república. A partir de estas fechas, empero, los proyectos fueron dirigidos cada vez más a los trabajadores mexicanos en Estados Unidos que se encontraban sin empleo. Al iniciarse la gran depresión a finales de 1929, el proceso de repatriación se aceleró, siendo estimulado en gran parte por la deportación forzosa de la que se habló anteriormente (Carreras, 1974:45-56; INEGI, 1985:4; Piñera y Verdugo, 1987 Vol. 3:167-168). La repatriación decreció al desatarse la segunda guerra mundial, que motivó una gran demanda de mano de obra mexicana por parte de la industria de guerra estadounidense y otros sectores de la economía, especialmente de la agricultura. Durante el primer cuarto de siglo después de la guerra, hubo otros intentos, oficiales y particulares, para repatriar a los mexicanos en Estados Unidos, pero estos esfuerzos luego disminuyeron a causa de la crisis económica de la década de 1980, con la consecuente decaída en el nivel de vida de los mexicanos en general y el desplome del peso frente al dólar (González, 1974 Vol. 2: 224-239).

\section{BIBLIOGRAFÍA}

ACUÑA, Rodolfo. 1976. América ocupada: los chicanos y su lucha de liberación. Ediciones Era. México.

BEAN, Frank D. y Martha Tienda. 1987. The Hispanic Population of the United States. Nueva York, Rusell Sage Foundation.

BEAN, Walton. 1978. California: An Interpretive History, Nueva York, McGraw Hill Book Company.

BURMA, Jonh H. 1974. Spanish Speaking Groups in the United States, 2da. ed. Detroit, Blaine Ethridge. 
BUSTAMANTE, Jorge A. 1990. Historia de la colonia Libertad, Tijuana, B.C. COLEF, Tijuana.

CARRERAS de Velasco, Mercedes. 1974. Los mexicanos que devolvi6 la crisis, 1929-1932. Secretaría de Relaciones Exteriores, México.

CONAPO. 1989. Estudio socioeconómico y demográfico del subsistema. (Volúmenes Nuevo Laredo-Reynosa-Matamoros y Tijuana-Mexicali-San Luis R. Colorado).

CORTÉS, Enrique. 1979. "Mexican Colonies During the Porfiriato", en: Aztlan: International Journal of Chicago Studies Research. Vol. 10, número especial (primavera-verano-otoño de 1979).

DAVIS Keitn A. 1972. "Tendencias demográficas urbanas durante el siglo XIX en México", en: Historia mexicana, Vol. 21, no. 3, enero-marzo. DE LEY, Margo. 1987. "Aspectos demográficos de la población mexicano-norteamericana del sureste de Estados Unidos". Los principales aspectos demográficos, sociales, poltticos y culturales de la comunidad mexicano-norteamericana y la Ley SimpsonRodino. CONAPO. México.

ESTRELLA Valenzuela, Gabriel. 1987. "Migración y población en la frontera norte", en: David Piñera Ramírez (coordinador). Vision histórica de la frontera norte de México. Vol. 3. Centro de Investigaciones Históricas UNAM-UABC. Tijuana.

FLORESCANO, Enrique (coordinador). 1983. Allas historico de México. Cultura SEP/siglo XXI editores.

GONZÁLEZ Navarro, Moisés. 1960. La Colonización en M'éxico, 1877 1910. Talleres de impresión de estampillas y valores. México.

- 1974. Población y sociedad en México, 1900-1970. Vol. I, II. UNAM. México.

HAM Chande, Roberto. 1987. "Trayectoria de un poblamiento: apuntes de un estudio demográfico", El Cotidiano, número especial 1.

HERNÁNDEZ Álvarez, José. 1967. "Perfil demográfico de la inmigración mexicana a los Estados Unidos, 1910-1950". Demografía yeconomía, Vol. I, no. 1.

HOWE Bancroft, Hubert. 1888. History of the North Mexican States and Texas (San Francisco, The History Company, 1888).

INEGI. 1985. Estadísticas historicas de México. México.

LÓPEZ Y RIVAS, Gilbcrto. 1979. Los chicanos: una minoria nacional explotada. 3ra. ed. Editorial Nuestro Tiempo.

MACIEL, David R. y José Carlos Romero. 1987. "Las comunidades chicanas al norte de la frontera". Visión histórica de la frontera norte de México. David Piñera R. (coordinador). Vol. 3. UNAMUABC. 
MARTÍNEZ, Óscar J. 1975. "On the Size of the Chicano Population: New Estimates, 1850-1900". Aztlán: International Journal of Chicano Studies Research, Vol. 6, no. 1, primavera 1975.

- 1982. Ciudad Juárez: El auge de una ciudad fronteriza a partir de 1848. Fondo de Cultura Económica. México.

MCWILLIAMS, Carey. 1979. Al norte de México: el conflicto entre "anglos" e "hispanos", 4ta. ed. Siglo XXI editores. México.

ORTEGA, Silvia. 1987. "El reverso de la medalla: la población de origen mexicano al norte del río Bravo". El Cotidiano. Número especial 1.1987.

PIÑERA Ramirez, David (Coord.). 1987. Vision historica de la frontera norte de México. Centro de Investigaciones Históricas, UNAMUABC. Vols. 1,2 y 3 .

PIÑERA Ramírez, David y Antonio Padilla Corona. 1987. "Las poblaciones fronterizas en la época porfiriana". Visión Histórica de la frontera norte de México. Vol. 2. Centro de Investigaciones Históricas UNAM-UABC.

PIÑERA Ramírcz, David y María Isabel Verdugo de Juárez. 1987. "La gran depresión y los repatriados". Visión Histórica de la frontera norte de México. Centro de Investigaciones Históricas UNAMUABC. Vol. 3.

SLATTA, Richard W. 1975. "Chicanos in the Pacific Northwest an Historical Overview of Oregon's Chicanos". Aztlan: International Journal of Chicano Studies Research. Vol. 6, no. 3. Otoño de 1975.

UNIKEL, Luis, Crescencio Ruiz Chapetto y Gustavo Garza Villarreal. 1978. El desarrollo urbano de México: diagnóstico e implicaciones futuras. El Colegio de México. México. 